\title{
SUKUK (OBLIGASI SYARIAH) DALAM PERSPEKTIF KEUANGAN ISLAM
}

\author{
Maula Nasrifah*
}

\begin{abstract}
Islam strongly encourages investment so that possessions can be productive and bring benefits in the future, of course, using a good and right way, which is in accordance with Islamic sharia, like mutual respect and does not harm others. The type of investment can be varied, we can invest through the capital market, one of which is sukuk. Sukuk are securities that are proof of ownership (claim) on assets, whether in the form of tangible, intangible or project contracts from certain activities that require the issuer to pay revenue-sharing to the Sukuk holders and pay back the Sukuk in maturity date. The principle in Sukuk transactions is in the form of emphasis on fair agreements, recommendations for profit sharing systems. In Sukuk transaction, a number of certain assets are needed which to used as the basis for conducting transactions using a contract based on sharia principles.

The types of Sukuk in terms of Sukuk Ijarah, Sukuk Mudharabah, Sukuk Musyarakah, Sukuk Istishna' with the method of issuing in bookbuilding, auction methods and private placement. In sukuk transactions there is a requirement for Underlying Assets as well as activities or processes which have been based in accordance with sharia. This shows that investing with sukuk is not worrying for investors who want to transact with sharia financial institutions.
\end{abstract}

Keywords: Investing, Transaction, Sukuk

* Dosen Tetap Fakultas Ekonomi dan Bisnis Islam Istitut Ilmu Keislaman Zainul hasan Genggong Kraksaan 


\section{PENDAHULUAN}

Investasi didalam islam sangat dianjurkan. Dalam kegiatan mu'amalat diperbolehkan bahkan dianjurkan untuk berinvestasi agar harta yang dimiliki menjadi produktif, berkembang dan pastinya mendatangkan manfaat untuk orang lain. Dengan berinvestasi itu berarti kita dapat menanamkan ataupun menempatkan aset kita untuk memberikan manfaat dan hasil dimasa mendatang. Konsep investasi dalam ajaran islam tidak hanya diwujudkan dalam bentuk finansial tetapi juga non finansial yang berimplikasi terhadap kehidupan ekonomi yang kuat. Dalam Al-Qur'an surat An nisa' ayat 9 berbunyi sebagai berikut:

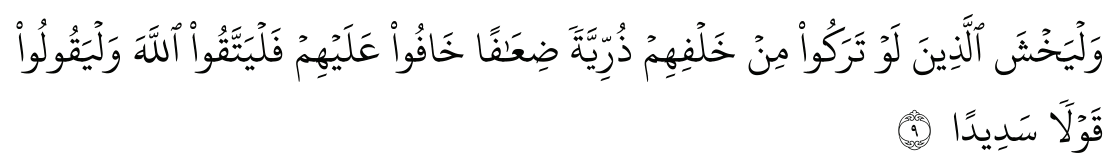

Artinya: Dan hendaklah takut kepada Allah SWT yang seandainya meninggalkan dibelakang mereka anak-anak yang lemah, yang mereka khawatir terhadap (kesejahteraan) mereka. Oleh sebab itu, hendaklah merekabertaqwa kepada Allah SWT dan mengucapkan perkataan yang jujur. (An nisa' : 9)

Ayat tersebut merupakan anjuran berinvestasi dengan mempersiapkan generasi yang kuat, baik aspek intelektualitas, fisik, keimanan maupun aspek ekonomi. Sedangkan landasan mengenai tata cara/panduan investasi yang baik, sehat dan benar didalam melakukan aktivitas perniagaan di sebutkan dalam Al Qur'an surat an Nisa' ayat 29 yang berbunyi sebagai berikut:

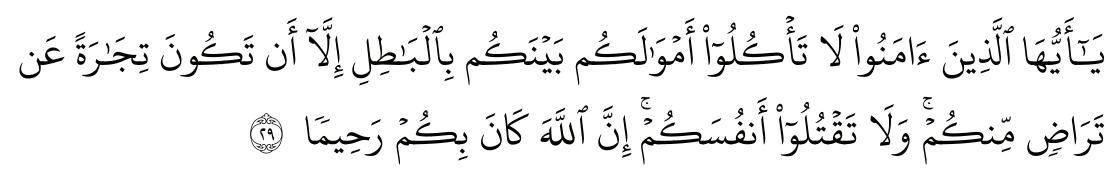

Artinya: Hai orang-orang beriman, janganlah kamu saling memakan harta sesamamu dengan cara yang batil, kecuali dengan jalan perniagaan suka sama suka diantara kamu dan janganlah kamu membunuh dirimu, sesungguhnya Allah SWT maha penyayang kepada dirimu.

Ayat tersebut merupakan panduan atau tata cara dalam berinvetasi yang sesuai dengan anjuran syariah dengan melakukan aktifitas 
perniagaan disertai rasa saling ridla bagi semua pihak yang terlibat yakni tidak merugikan orang lain dan lebih hati-hati didalam menginvestasikan harta yang dimiliki guna mencapai tujuan menerima manfaat dimasa yang akan datang. Investasi keuangan merupakan sebuah investasi yang bertujuan mulia seperti yang disebutkan pada paparan sebelumnya.

Sedangkan Investasi keuangan menurut syariah yang dikemukakan Ahmad Ghozali dapat berkaitan dengan kegiatan perdagangan atau usaha yang berkaitan dengan suatu produk atau aset maupun usaha jasa. ${ }^{1}$ Saat ini banyak pilihan untuk menanamkan modal dalam bentuk investasi. Salah satu bentuk investasi adalah menanamkan dana pada suatu surat berharga yang diharapkan akan meningkat nilainya dimasa mendatang melalui pasar modal.

Pasar modal pada dasarnya merupakan pasar untuk berbagai instrumen keuangan atau surat-surat berharga jangka panjang yang bisa diperjualbelikan, baik dalam bentuk utang maupun modal sendiri. Jika Dilihat dari sisi syariah, pasar modal merupakan salah satu sarana untuk bermu'amalah. Transaksi di pasar modal menurut hukum syariah tidak dilarang atau diperbolehkan sepanjang tidak terdapat transaksi yang bertentangan dengan syariah. Seperti yang dikemukaan Nur Rianto pada dasarnya pasar modal syariah adalah pasar modal yang menerapkan prinsip-prinsip syariah dalam kegiatan transaksi ekonomi dan terlepas dari hal-hal yang dilarang oleh syariah seperti adanya unsur riba, judi, spekulasi dan lain-lain yang dapat merugikan semua pihak yang terlibat didalamnya. ${ }^{2}$

Sejumlah instrumen syariah sudah diterbitkan di pasar modal syariah, seperti saham syariah, obligasi syariah (Sukuk), reksadana syariah, dan surat berharga lain yang sesuai dengan prinsip syariah. Investasi dengan kepemilikan sekuritas syariah dapat dilakukan dipasar modal syariah, baik secara langsung saat penawaran perdana maupun transaksi perdagangan sekunder di bursa efek.

Dari berbagai jenis sekuritas yang ada, beberapa diantaranya telah memperoleh pengakuan dari Dewan syariah nasional (DSN) atas

1 Ahmad Gozali, Halal, berkah, bertambah. Mengenal dan memilih produk investasi syariah (Jakarta: Elex Media Komputindo, 2004), hal. 17

2 M. Nur Rianto Al arif, Lembaga Keuangan Syariah (Bandung: CV. Pustaka Setia,2012) Hal. 345 
kesyariahannya, baik itu saham syariah, reksadana, maupun obligasi syariah atau yang lebih dikenal dengan Sukuk. Sukuk merupakan terobosan baru dalam dunia keuangan islam yang merupakan bentuk pendanaan dan sekaligus investasi. Tulisan ini membahas tentang Sukuk yang dalam fatwa DSN disebut obligasi syariah, baik itu pengertian, sejarah, prinsip-prinsip, karateristik, akad-akad, manajemen serta bagaimana metode pemasaran Sukuk agar Sukuk menjadi lebih dikenal dan berkembang selayaknya industri keuangan syariah lainnya.

\section{PEMBAHASAN}

\section{Pengertian Sukuk}

Obligasi Syariah didunia internasional dikenal nama Sukuk. Kata Sukuk dapat ditelusiri dengan mudah pada literature islam komersial klasik. Sukuk berasal dari bahasa arab "sak" (tunggal) dan "Sukuk" (jama') yang memiliki arti mirip dengan sertiifkat atau note. Menurut Iggi H. Ahsien dalam Muhamamd Kamal Zubair Dalam pemahaman praktisnya, Sukuk merupakan bukti (claim) kepemilikan. ${ }^{3}$

Didalam fatwa DSN-MUI Nomor 32/DSN-MUI/IX/2012, DSN masih menggunakan istilah Obligasi Syariah, belum menggunakan istilah Sukuk. Jika mengaju kepada fatwa tersebut Obligasi Syariah adalah suatu surat berharga jangka panjang berdasarkan prinsip syariah yang dikeluarkan emiten kepada pemegang obligasi syariah yang mewajibkan emiten untuk membayar pendapatan kepada pemegang obligasi syariah berupa hasil/margin/fee serta membayar kembali dana obligasi pada saat jatuh tempo.

AAOIFI (Accounting and Auditing Organization for Islamic Financial Insitution) mendefinisikan Sukuk sebagai sertifikat dari suatu nilai yang direpresentasikan setelah penutupan pendaftaran, bukti terima nilai sertifikat dan menggunakannya sesuai dengan rencana, sama halnya dengan bagian dan kepemilikan atas asset yang tangible, barang, atau jasa, atau modal dari suatu proyek tertentu atau modal dari suatu aktifits

3 Muhammad Kamal Zubair, Obligasi dan Sukuk dalam perspektif keuangan Islam (Jurnal: Asy-Syir'ah, Jurnal Ilmu Syariah dan Hukum, Vol. 46 No. 1 Januari-Juni 2012) 
tertentu. $^{4}$

Sedangkan menurut Bapepam dan Lembaga Keuangan No. IX.A.13 tentang penerbitan efek syariah memberikan definisi Sukuk sebagai berikut: Efek syariah berupa sertifikat atau bukti kepemilikan yang bernilai sama dan mewakili bagian yang tidak tertentu (tidak terpisahkan atau tidak terbagi /syuyu'/undivided share) atas: Aset wujud tertentu, nilai manfaat, jasa, aset proyek ataupun kegiatan investasi yang telah ditentukan.

Dari pengertian-pengertian tersebut diatas dapat disimpulkan bahwa Sukuk atau obligasi syariah adalah surat berharga yang merupakan bukti kepemilikan (claim) atas aset, baik itu berupa tangible, intangible ataupun kontrak proyek dari aktifitas tertentu yang mewajibkan emiten membayar pendapatan bagi hasil kepada pemegang Sukuk dan membayar kembali Sukuk sesuai dengan tanggal jatuh tempo yang sudah disepakati. Dan dalam kegiatan mulai dari transaksi dikeluarkannya surat berharga tersebut sampai kepada aktivitas penyerahan hasil harus sesuai dengan prinsip syariah.

Untuk lebih memudahkan dan memperjelas persamaan \& perbedaan Obligasi Syariah (Sukuk) dan obligasi konvensional akan digambarkan dalam bentuk table berikut: ${ }^{5}$

\begin{tabular}{|l|l|l|l|}
\hline \multirow{2}{*}{$\begin{array}{c}\text { Variabel } \\
\text { Pembeda }\end{array}$} & \multicolumn{2}{|c|}{ Obligasi Syariah (Sukuk) } & \multicolumn{1}{c|}{$\begin{array}{c}\text { Obligasi } \\
\text { Konvensional }\end{array}$} \\
\cline { 2 - 3 } & \multicolumn{1}{c|}{ Mudharabah } & \multicolumn{1}{c|}{ Ijarah } \\
Akad (Transaksi) & $\begin{array}{l}\text { Mudharabah } \\
\text { (Bagi Hasil) }\end{array}$ & $\begin{array}{l}\text { Ijarah (Sewa/ } \\
\text { Lease) }\end{array}$ & Tidak ada \\
\hline Jenis Transaksi & $\begin{array}{l}\text { Uncertainty } \\
\text { Contract }\end{array}$ & $\begin{array}{l}\text { Certainty } \\
\text { Contract }\end{array}$ & $\begin{array}{l}\text { Instrument } \\
\text { Pengakuan } \\
\text { Utang }\end{array}$ \\
\hline Penerbit & $\begin{array}{l}\text { Pemerintah, } \\
\text { Korporasi }\end{array}$ & $\begin{array}{l}\text { Pemerintah, } \\
\text { Korporasi }\end{array}$ & $\begin{array}{l}\text { Pemerintah, } \\
\text { Korporasi }\end{array}$ \\
\hline
\end{tabular}

4 AAOIFI merupakan lembaga nirlaba internasional yang bertujuan menyusun dan menyiapkan standarisasi di bidang keuangan syariah, khususnya terkait dengan tekhnik akuntansi, audit, governace, ethics, dan kesesuaian prinsip-prinsip syariah atas produk keuangan syariah.

5 Khaerul Umam, Pasar Modal Syariah Eु Praktik Pasar Modal Syariah (Bandung: Pustaka Setia, 2013) hal. 174-175. 


\begin{tabular}{|c|c|c|c|}
\hline $\begin{array}{l}\text { Pihak yang } \\
\text { terkait }\end{array}$ & $\begin{array}{l}\text { Obligor, SPV, } \\
\text { Investor, trustee }\end{array}$ & $\begin{array}{l}\text { Obligor, SPV, } \\
\text { Investor, trustee }\end{array}$ & $\begin{array}{l}\text { Obligor/Issuer, } \\
\text { Investor }\end{array}$ \\
\hline $\begin{array}{l}\text { Harga } \\
\text { Penawaran }\end{array}$ & $100 \%$ & $100 \%$ & $100 \%$ \\
\hline $\begin{array}{l}\text { Kupon/ } \\
\text { Penghasilan }\end{array}$ & $\begin{array}{l}\text { Pendapatan/ } \\
\text { Bagi Hasil }\end{array}$ & Imbalan/Fee & Bunga/Riba \\
\hline $\begin{array}{l}\text { Pembayaran } \\
\text { Pokok }\end{array}$ & $\begin{array}{l}\text { Bullet atau } \\
\text { Amortisasi }\end{array}$ & $\begin{array}{l}\text { Bullet atau } \\
\text { Amortisasi }\end{array}$ & $\begin{array}{l}\text { Bullet atau } \\
\text { Amortisasi }\end{array}$ \\
\hline Jangka Waktu & $\begin{array}{l}\text { Pendek- } \\
\text { Menegah }\end{array}$ & $\begin{array}{l}\text { Pendek- } \\
\text { Menegah }\end{array}$ & $\begin{array}{l}\text { Menengah- } \\
\text { Panjang }\end{array}$ \\
\hline Pengembalian & $\begin{array}{l}\text { Indikatif } \\
\text { berdasarkan } \\
\text { pendapatan/ } \\
\text { income }\end{array}$ & $\begin{array}{l}\text { Ditentukan } \\
\text { sebelumnya }\end{array}$ & Float/Tetap \\
\hline Underlying Asset & Perlu & Perlu & Tidak perlu \\
\hline Jenis Investor & $\begin{array}{l}\text { Syariah/ } \\
\text { Konvensional }\end{array}$ & $\begin{array}{l}\text { Syariah/ } \\
\text { Konvensional }\end{array}$ & Konvensional \\
\hline Akibat & Halal & Halal & Haram \\
\hline Hukum & $\begin{array}{l}\text { Maslahat dunia } \\
\& \text { akhirat }\end{array}$ & $\begin{array}{l}\text { Maslahat dunia } \\
\& \text { akhirat }\end{array}$ & Mudharat \\
\hline Harga & Harga Pasar & Harga Pasar & Harga Pasar \\
\hline $\begin{array}{l}\text { Penggunaan } \\
\text { Hasil Penerbitan }\end{array}$ & $\begin{array}{l}\text { Harus sesuai } \\
\text { syariah }\end{array}$ & $\begin{array}{l}\text { Harus sesuai } \\
\text { syariah }\end{array}$ & Bebas \\
\hline
\end{tabular}

Sumber: Pendapat Khairul Umam dalam bukunya Pasar Modal Syariah

\section{Landasan Hukum Sukuk}

\section{Al Qur'an Surat Al-Baqarah: 275}

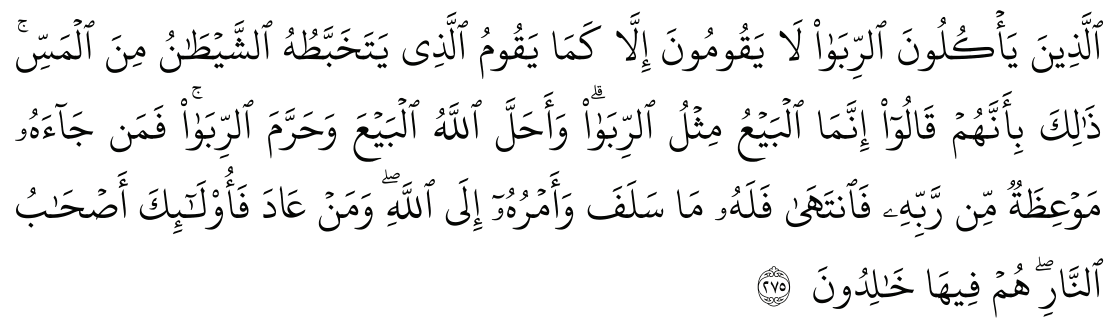


Artinya: "Orang-orang yang makan (mengambil) riba tidak dapat berdiri melainkan seperti berdirinya orang yang kemasukan syaitan lantaran (tekanan) penyakit gila. Keadaan mereka yang demikian itu, adalah disebabkan mereka berkata (berpendapat), sesungguhnya jual beli itu sama dengan riba, padahal Allah telah menghalalkan jual beli dan mengharamkan riba. Orang-orang yang telah sampai kepadanya larangan dari Tuhannya, lalu terus berhenti (dari mengambil riba), maka baginya apa yang telah diambilnya dahulu (sebelum datang larangan); dan urusannya (terserah) kepada Allah. Orang yang kembali (mengambil riba), maka orang itu adalah penghuni-penghuni neraka; mereka kekal di dalamnya".

\section{Hadits Nabi Riwayat Imam al-Tirmidzi dari 'Amr bin 'Auf al- Muzani}

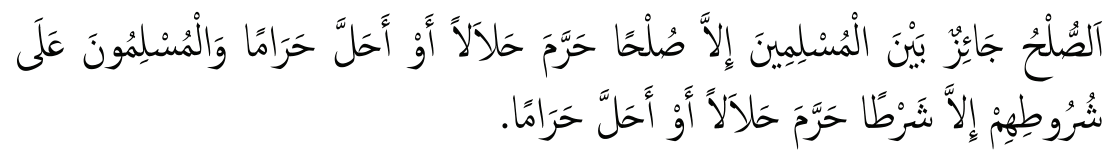

Artinya: "Perjanjian boleh dilakukan di antara kaum muslimin kecuali perjanjian yang mengharamkan yang halal atau menghalalkan yang haram; dan kaum muslimin terikat dengan syarat-syarat mereka kecuali syarat yang mengharamkan yang halal atau menghalalkan yang haram."

\section{Kaidah Fiqh}

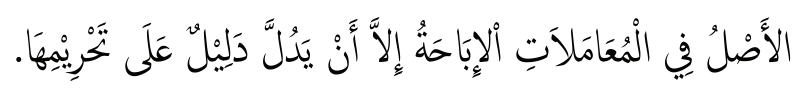

Artinya: "Pada dasarnya, semua bentuk mu'amalah boleh dilakukan, kecuali ada dalil yang mengharamkannya".

\section{Prinsip-Prinsip Sukuk}

Pada prinsipnya Sukuk mirip seperti obligasi konvensional. Persamaan dan perbedaannya seperti yang telah diuraikan pada table sebelumnya. Selain itu Sukuk juga distruktur secara islam sehingga terbebas dari riba, gharar dan maysir. ${ }^{6}$

${ }^{6}$ Nurul huda \& M Heykal, Lembaga Keuangan Islam Tinjauan Teoritis dan Praktik (Jakarta: Kencana Media Group, 2010) hal 265 
Prinsip pokok dalam transaksi Sukuk ini berupa penekanan pada perjanjian yang adil, anjuran atas system bagi hasil atau profit sharing. Dalam transaksi Sukuk ini juga diperlukan sejumlah asset tertentu yang digunakan sebagai dasar dalam melakukan transaksi dengan menggunakan akad berdasarkan prinsip syariah.

\section{Karateristik Sukuk}

a. Merupakan bukti kepemilikan suatu asset berwujud atau hak manfaat (benefial title)

b. Pendapatan berupa imbalan (Kupon), Margin, dan bagi hasil sesuai jenis akad yang digunakan.

c. Terbebas dari unsur riba, gharar, maisir

d. Penerbitannya melalui Spesial Purpose Vechile (SPV)

e. Memerlukan underlying asset

f. Penggunaan proceeds harus sesuai prinsip islam

\section{Akad-Akad/Jenis-Jenis Sukuk}

Jenis Sukuk yang direkomendasikan oleh AAOIFI adalah sebagai beriku:

a. Sukuk Ijarah merupakan Sukuk yang diterbitkan berdasarkan perjanjian atau akad ijarah dimana satu pihak bertindak sendiri atau melalui wakilnya menjual atau menyewakan hak manfaat atas suatu asset kepada pihak lain berdasarkan harga dan periode yang disepakati, tanpa diikuti dengan pemindahan kepemilikan asset itu sendiri.

b. Sukuk Mudharabah yakni Sukuk yang diterbitkan dengan akad mudharabah, keuntungan dari kerjasama tersebut akan dibagi berdasarkan perbandingan yang telah disepakatibersamasebelumnya. Sedangkan kerugian yang timbul sepenuhnya ditanggung oleh pemilik modal (Shahibul mal).

c. Sukuk Musyarakah yakni Sukuk yang diterbitkan berdasarkan perjanjian musyarakah dimana dua pihak atau lebih bekerjasama menggabungkan modal untuk membangun proyek baru, mengembangkan proyek yang sudah ada atau membiayai kegiatan 
usaha. Keuntungan ataupun kerugian yang timbul ditanggung bersama sesuai dengan partisipasi modal masing-masing pihak.

d. Sukuk Istisna' yakni Sukuk yang diterbitkan akad istisna' dimana para pihak menyepakati jual beli dalam rangka pembiayaan suatu proyek atau barang. Adapun harga, waktu penyerahan dan spesifikasi barang/proyek ditentukan terlebih dahulu berdasarkan kesepakatan.

\section{Manajemen Sukuk}

Dalam pembahasan sub manajemen Sukuk akan dijelaskan terperinci mulai dari penerbitan Sukuk, pihak-pihak yang terlibat, jangka waktu dan sifat imbalan Sukuk.?

\section{A. Metode Peneribatan Sukuk}

Penerbitan Sukuk, sesuai dengan international best practice, dapat dilakukan dengan cara/Metode:

a. Bookbuilding adalah salah satu metode penerbitan surat berharga, yaitu investor akan menyampaikan penawaran pembelian atas suatu surat berharga, biasanya berupa jumlah dan harga (yield) penawaran pembelian, dan dicatat dalam book order oleh investment bank yang bertindak sebagai bookrunner.

b. Metode Lelang adalah metode penerbitan dan penjualan surat berharga yang diikuti oleh peserta lelang dengan cara mengajukan penawaran pembelian kompetitif dan/atau penawaran pembelian nonkompetitif dalam suatu periode waktu penawaran yang telah ditentukan dan diumumkan sebelumnya, melalui sistem yang disediakan oleh agen yang melaksanakan lelang.

c. Private placement adalah salah satu metode penerbitan surat berharga, dimana kegiatan penerbitan dan penjualan surat berharga dilakukan oleh pihak penerbit kepada pihak tertentu dengan ketentuan dan persyaratan (terms $\mathscr{E}$ conditions) yang disepakati bersama.

Penerbitan Sukuk pada umumnya dilakukan melalui (Special Purpose Vehicle) SPV sebagai penerbit, namun dapat pula dilakukan secara langsung oleh originator/obligor.

7 Pada sub pembahasan manajemen Sukuk banyak mengutip buku Tanya jawab Surat berharga Syariah Negara/Sukuk Negara yang diterbitkan oleh Direktorat Pembiayaan Syariah. 
B. Pihak-pihak yang terlibat dalam penerbitan Sukuk

Pihak-pihak yang terlibat dalam penerbitan Sukuk antara lain sebagai berikut:

1. Obligor, yaitu pihak yang bertanggung jawab atas pembayaran pokok serta imbal hasil Sukuk yang diterbitkan

2. Special Purpose Vehicle (SPV) yaitu badan hukum yang didirikan khusus untuk menerbitkan Sukuk

3. Investor yaitu pihak pemegang Sukuk yang memiliki hak kepentingan atas underlying asset melalui SPV

4. Sharia Advisor yaitu sebagai pihak yang memberikan fatwa atau pernyataan kesesuaian terhadap prinsip-prinsip syariah atas Sukuk yang diterbitkan

5. Wali Amanat yaitu pihak yang mewakilli kepentingan pemegang Sukuk sesuai dengan yang diperjanjikan.

\section{Jangka Waktu (Tenor) Sukuk}

Berdasarkan Standar Syariah The Accounting and Auditing Organization for Islamic Financial Institutions (AAOIFI) nomor 17 tentang Sukuk Investasi, penerbitan Sukuk boleh dilakukan untuk jangka pendek, jangka menengah dan jangka panjang, sesuai dengan prinsip-prinsip syariah yang mendasari penerbitannya. Selain itu, Sukuk juga dapat diterbitkan tanpa ditentukan jangka waktunya, mengacu pada akad yang digunakan dalam penerbitan Sukuk.

\section{Sifat imbalan Sukuk}

Imbalan (kupon) Sukuk dapat bersifat tetap (fixed rate) atau mengambang (floating), sesuai dengan jenis akad dan struktur yang digunakan dalam penerbitan. Imbalan Sukuk tersebut biasanya dinyatakan dalam bentuk persentase dan dibayarkan secara periodik sesuai ketentuan dan persyaratan yang ada dalam penerbitan Sukuk (terms and conditions).

\section{Sejarah/Perkembangan Sukuk Di Indonesia}

Secara umum, pasar keuangan syariah internasional terus mengalami perkembangan yang sangat pesat. Saat ini jumlah lembaga 
keuangan syariah global telah mencapai sekitar 810 perusahaan yang tersebar di 50 negara. Sekitar 450 lembaga keuangan syariah beroperasi di kawasan Timur Tengah, terutama UEA, Bahrain, Kuwait, Iran dan Saudi Arabia. Di Eropa, sekitar 114 lembaga keuangan syariah menjadi pelaku di pasar keuangan syariah Eropa yang terkonsentrasi di Inggris. Sedangkan di Amerika Utara, jumlah lembaga keuangan syariah masih relatif sedikit, yaitu sekitar 44 yang tersebar di AS dan Kanada (Sumber: Bank Indonesia). ${ }^{8}$

Seiring dengan perkembangan pasar keuangan syariah internasional, pasar keuangan syariah di Indonesia juga tumbuh dan berkembang dengan pesat. Pesatnya perkembangan industri keuangan syariah juga diikuti oleh pesatnya perkembangan instrumen keuangan dan pembiayaan syariah salah satunya Sukuk atau yang lebih dahulu dikenal dengan obligasi syariah.

Di Indonesia pada tahun 2008 akhirnya mencatkan sejarah baru. Meski terlambat yaitu pada bulan Mei 2008, pemerintah telah mengundang-undangkan No. 19/2008 tentang surat berharga (SBDN) atau UU Sukuk Negara (Sovereign Sukuk), hal ini patut diberikan apresiasi tinggi atas upaya pemerintah yang berhasil mensahkan UU Sukuk Negara ini. Dikatakan terlambat, karena perkembangan Sukuk di Indonesia sesungguhnya sudah dimulai swasta, meskipun pangsanya masih kecil.

Dengan berlakuknyaUUSukuk Negara dan adanya penerbitan Sukuk oleh pemerintah, itu berarti Sukuk kini menjadi instrument pembiayaan yang diakui sehingga dapat meningkatkan kepercayaan investor terhadap Sukuk kita, baik Sukuk Negara maupun Sukuk korporasi. dimulai dengan adanya Sovereign Sukuk. Dengan diberlakukannya UU Sukuk Negara, diperkirakan perkembangan pasar Sukuk di Indonesia akan lebih semarak dibandingkan sebelumnya. Terlebih lagi, minat investor terhadap Sukuk ini sangat besar, sebagaimana ditunjukkan dari perkembangan Sukuk global saat ini. Adapun data perkembangan Sukuk di Indonesia berdasarkan data dari OJK (Otoritas Jasa keuangan) selalu megalami penigkatan baik dalam jumlah total nilai dan jumlah emisi Sukuk dan Sukuk outstanding. Data terlampir.

8 Tanya Jawab Surat berharga Syariah Negara/Sukuk Negara yang dicetak oleh Direktorat Pembiayaan Syariah. 2010 Edisi Kedua. 
Berikut Faktor-faktor yang menyebabkan pesatnya perkembangan instrumen keuangan syariah khususnya Sukuk, diantaranya: (1) Adanya kebutuhan pendanaan yang bersifat spesifik dan memerlukan struktur Sukuk yang baru. (2) Semakin meningkatnya partisipasi investor konvensional di pasar keuangan syariah. (3) Besarnya kebutuhan sektor perbankan dan lembaga keuangan syariah lainnya untuk portofolio investasi. (4) Besarnya partisipasi aktif dari para pelaku pasar, ekonom, pakar syariah, dan para stake-holder keuangan syariah lainnya untuk menciptakan struktur baru yang sesuai dengan prinsip syariah. (5) Potensi permintaan terhadap Sukuk Negara oleh investor domestik dan luar negeri diperkirakan sangat tinggi, dengan mengacu pada kondisi antara lain: tingginya peningkatan jumlah lembaga keuangan syariah, market share produk syariah dibandingkan produk konvensional relatif masih sangat kecil, tingginya kecenderungan negara-negara yang berpenduduk minoritas muslim untuk mengadopsi konsep keuangan syariah, banyaknya investor konvensional menggunakan instrumen keuangan berbasis syariah sebagai salah satu pilihan investasi, repatriasi dana-dana Timur Tengah dari pasar Amerika dan Eropa pasca peristiwa 9/11, masih terbatasnya instrumen keuangan syariah dibandingkan dengan permintaan; dan terus meningkatnya peringkat kredit (credit rating) Indonesia.

\section{Strategi Pemasaran Sukuk}

Bagi pemerintah ataupun swasta yang ingin memasarkan Sukuk yang sudah mereka terbitkan harus memiliki tips dan trik berikut ini agar Sukuk dapat diterima dan diminati oleh pasar baik domestik maupun internasional:

a. Sukuk yang diterbitkan harus memenuhi semua ketentuan syariah, antara lain proses penerbitannya, penggunaan dana hasil penerbitannya, maupun yang terkait dengan underlying asset.

b. Likuiditas (marketability of instrument), yaitu Sukuk harus dapat dipindahtangankan dari satu pihak ke pihak lain (transferable) dan harus dapat diperjualbelikan (tradable).

c. Tingkat imbalan yang kompetitif dibandingkan instrumen keuangan lainnya. 
d. Transparansi, berupa kejelasan dan kemudahan akses informasi bagi investor.

e. Proses penerbitan mengikuti ketentuan yang umum berlaku dalam penerbitan Sukuk di pasar keuangan internasional.

f. Adanya dukungan infrastruktur legal dan kelembagaan yang memadai, termasuk dukungan pasar keuangan yang efisien

Memasarkan Sukuk kedalam pasar sekunder diperolehkan karena pada prinsipnya, Sukuk adalah bukti kepemilikan investor atas aset/ manfaat/jasa dan bukan merupakan surat utang. Sehingga berdasarkan prinsip syariah, perdagangan/jual beli Sukuk di pasar sekunder dibolehkan karena pada dasarnya yang diperjualbelikan adalah aset/manfaat/jasa yang menjadi underlying asset Sukuk, bukan jual beli hutang. Hal tersebut sesuai dengan pasal 5/2 Standar Syariah AAOIFI Nomor 17 tentang Sukuk Investasi, yang memperbolehkan perdagangan/jual beli Sukuk.

Namun demikian, perdagangan Sukuk tetap memperhatikan struktur dan jenis akad yang melandasi penerbitannya. Hal itu dikarenakan terdapat beberapa jenis struktur Sukuk yang tidak dapat diperdagangkan, misalnya Sukuk dengan struktur Istishna $\square$, Salam, dan Murabahah. Ketentuan mengenai dibolehkannya perdagangan suatu Sukuk dapat diketahui dari terms and conditions yang tercantum pada memorandum informasi penerbitan Sukuk.

\section{PENUTUP}

Sukuk merupakan salah satu instrumen dalam pasar keuangan syariah. Adanya persyaratan harus ada Underlying Aset serta kegiatan atau proses yang didalamnya sudah berlandaskan sesuai dengan syariah menunjukkan bahwa berinvestasi dengan sukuk tidak menghawatirkan bagi investor yang ingin bertransaksi dengan lembaga keuangan syariah. Sebagaimana disebutkan diawal dalam pembahasan ini, investasi kita saat ini bertujuan untuk mempersiapkan kebutuhan dimasa depan. 


\section{DAFTAR PUSTAKA}

Al-Qur'an

Al-Hadits

Ali, Nur Rianto, 2012, Lembaga Keuangan Syariah, Bandung: CV PUSTAKA SETIA

Direktorat Pembiayaan Syariah, 2010, Tanya Jawab Surat berharga Syariah Negara/Sukuk Negara Edisi Kedua.

Ghozali Ahmad, 2004, Halal, berkah, bertambah. Mengenal dan memilih produk investasi syariah, Jakarta: Elex Media Komputindo.

Huda \& Haekal, 2010, LEMBAGA KEUANGAN ISLAM Tinjauan Teoritis 8 Praktis, Jakarta: KENCANA PREDANA MEDIA GROUP

Nugroho, Hadityo, 2013, AKUNTANSI SYARIAH Perkembangan Sukuk Dunia, Skripsi FE UI.

Umar, Kaherul, 2013, PASAR MODAL SYARIAH $\&$ Praktik Pasar Modal Syariah, Bandung: CV Pustaka Setia

Wahid, Nazaruddin Abdul, 2010, SUKUK Memahami 83 Membedah Obligasi Pada Perbankan Syariah, Jogjakarta: Ar Ruzz Media.

Zubair, Muhammad Kamal, 2012, Obligasi dan Sukuk dalam perspektif keuangan Islam, Asy-Syir'ah, Jurnal Ilmu Syariah dan Hukum, Vol. 46 No. 1 Januari-Juni 2012

http://www.djppr.kemenkeu.go.id/uploads/files/dmodata/ in/6Publikasi/5Brosur/Buku_Tanya_Jawab_SBSN_Edisi_ Kedua_2010.pdf. diakses Oktober $201 \overline{5}$

http://ib.unnes.ac.id/18062/1/7350408044.pdf. diakses Oktober 2015

http://repository.uinjkt.ac.id/dspace/bitstream/123456789/4098/1/ FAHMI\%20SALIM-FSH.pdf. diakses Oktober 2015

http://repository.usu.ac.id/bitstream/123456789/26168/3/Chapter\%20 II.pdf. diakses Oktober 2015

http://repository.widyatama.ac.id/xmlui/bitstream/handle/123456789/2527/ MOCHAMAD\%20RIZKI\%20PRATAMA\%20\%200109U010). pdf?sequence $=1$. diakses Oktober 2015 
http://digilib.uin-suka.ac.id/13339/1/BAB\%20I,\%20V,\%20 DAFTAR\%20PUSTAKA.pdf. diakses Oktober 2015

http://journal.uin-suka.ac.id/media/artikel/ASY124601-91-113-1-PB. pdf diakses Oktober 2015 